\title{
ARTIGOS
}

\section{PROSPECTANDO HORIZONTES PARA 0 \\ ENSINO INTEGRADO DA SUSTENTABILIDADE \\ NA EDUCAÇÃO BÁSICA}

\section{PROSPECTING HORIZONS FOR INTEGRATED TEACHING OF SUSTAINABILITY IN BASIC EDUCATION}

\author{
VERÔNICA BATISTA DE LIMA | UFF \\ DOUGLAS VIEIRA BARBOZA, M.SC.|UFF \\ MARCELO JASMIM MEIRIÑO, Dr. | UFF \\ RICARDO LUIZ FERNANDES BELLA, Dr. | UFF
}

\begin{abstract}
RESUMO
Este trabalho buscou analisar o ensino da sustentabilidade nas escolas de educação básica, em especial, no contexto do ensino de ciências. Como metodologia de pesquisa foram realizadas entrevistas de cunho qualitativo com questões abertas à professores do primeiro ciclo do ensino fundamental que lecionam ciências em três escolas públicas e coordenadores pedagógicos que atuam na educação básica. Os resultados evidenciaram a necessidade de promover ações de disseminação do conhecimento sobre sustentabilidade para além do ensino de ciências. A principal contribuição deste artigo é a verificar o panorama atual do ensino da sustentabilidade na educação básica para traçar perspectivas ou diretrizes de ensino futuras.
\end{abstract}

PALAVRAS CHAVE: Desenvolvimento Sustentável; Educação Ambiental; Ensino de Ciências

\begin{abstract}
This work sought to analyze the teaching of sustainability in basic education schools, especially in the context of science teaching. As a research methodology, qualitative interviews were conducted with questions open to teachers of the first cycle of elementary school who teach science in three public schools and to pedagogical coordinators who work in basic education. The results showed the need to promote actions to disseminate knowledge about sustainability beyond science teaching. The main contribution of this article is to verify the current panorama of the teaching of sustainability in basic education in order to outline future teaching perspectives or guidelines.
\end{abstract}

KEY WORDS: Sustainable Development; Environmental education; Science teaching 


\section{INTRODUÇÃO}

De acordo com Muniz \& Pazmino (2019), a educação ambiental trata de integrar novos conhecimentos, valores e capacidades com potencial para criar uma consciência ambiental dos indivíduos.

Uma educação voltada para a sustentabilidade é um fator positivo para o crescimento de saberes a serem estimulados em sala de aula, através da dinâmica fornecida pelos educadores aos alunos, como forma de instigar a produção de conhecimento e interesse para causas que tragam atitudes benéficas para o seu desenvolvimento pessoal e da sociedade como um todo.

O presente artigo objetiva abordar a relação do conhecimento sobre sustentabilidade dentro da sala de aula, juntamente com o conhecimento dos docentes sobre o tema e suas ações didaticamente planejadas, e de que forma as leis vigentes sobre educação ambiental podem contribuir para desenvolver uma atitude mais consciente sobre a questão.

Considerando que pilares como as políticas econômicas e sociais devem estar contempladas dentro de um ensino em prol do desenvolvimento sustentável, ou seja, o meio ambiente, a sociedade e a economia devem ser vistos de modo interconectado, conforme se pode perceber na Figura 1.

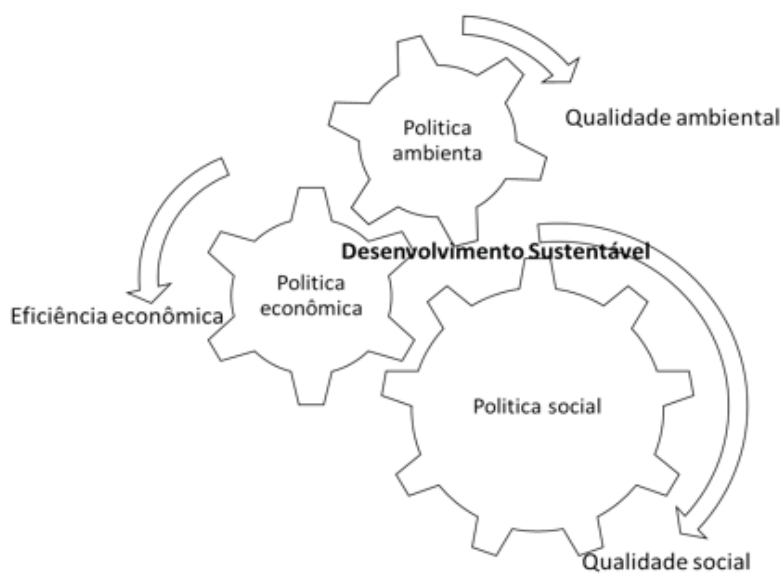

Figura 1 - Interconexão das três dimensões do desenvolvimento sustentável Fonte: Barboza et al., 2019

De acordo com Pereira et al. (2018), a pesquisa pode ser classificada como uma pesquisa aplicada quanto a natureza, com abordagem qualitativa e de forma exploratória quanto aos seus objetivos. O procedimento técnico se deu através de pesquisas bibliográficas, documentais e levantamento.

Metodologicamente, os referenciais teóricos básicos foram amparados na legislação sobre a temática como os PCN (BRASIL, 1997), o Programa Nacional de Educação Ambiental (BRASIL, 2005), e as publicações de Miller e Spoolman (2012) e Barbosa (2008).
Na pesquisa empírica, o método utilizado foi qualitativo, através da coleta de depoimentos feitos por professores e coordenadores pedagógicos, que há algum tempo lecionam e vivenciam práticas interdisciplinares sobre a temática, utilizando como recorte, aqueles que atuam no município de Araruama no Rio de Janeiro.

$\mathrm{O}$ artigo divide-se em duas seções. Na primeira seção, um breve histórico definindo o conceito de sustentabilidade, e suas finalidades sobre a necessidade de se manter em um ambiente equilibrado. Na segunda seção, foi retratado o tema sustentabilidade no ensino de Ciências, com contribuição da análise dos depoimentos de educadores (professores e coordenadores), de como programar situações didáticas intencionalmente planejadas, afim de desenvolver maior apreço por uma prática sustentável no espaço escolar, onde o aluno está inserido, perpertuando por toda a coletividade.

Além disso, também, é esperada a geração de maior interesse para novas pesquisas relacionadas ao tema.

\section{REVISÃO DE LITERATURA}

A questão ambiental é o primeiro ponto dentro da sustentabilidade a ser debatido, tendo atenção em diversas conferências e documentos, como o Clube de Roma, a Conferência de Estocolmo, o Relatório "Nosso Futuro Comum", a ECO 92, o Protocolo de Kyoto, dentre outros, com o intuito de buscar diretrizes que sejam sustentáveis para o mundo (GONÇALVES, et al., 2019).

Já o termo sustentabilidade em si surge do entendimento mais amplo sobre atender as necessidades das gerações existentes e a ter grande preocupação com as novas que irão surgir (ELKINGTON, 1999). As mudanças ocasionadas pela degradação dos recursos oferecidos pela natureza trazem a percepção da sociedade em tentar equilibrar o uso dos ecossistemas para que as futuras gerações consigam viver em um mundo melhor (BOFF, 2012). Nesse sentido, o termo sustentabilidade é caracterizado por manter o cuidado com o planeta, podendo usufruir das maravilhas da terra, não só para a população presente, como também para as gerações futuras (MILLER; SPOOLMAN, 2012).

Entende-se nesse contexto que a manutenção dos recursos naturais oferecidos pela Terra está relacionada com a maneira como a população existente manuseia esses recursos, de modo que venha durar em longo prazo (BOECHAT, 2012). Outro aspecto levantado por Miller e Spoolman (2012), seria o capital natural, onde os recursos e serviços fornecidos pela natureza nos mantém, e nos sustenta. Dessa forma, o uso consciente e sustentável desse capital, pode fazê-lo durar por tempo indeterminado, propiciando a diversidade de espécies na Terra. 
Miller e Spoolman (2012, p. 28) citam o naturalista Henry David Thoreau para contribuir com a ideia de um planeta sustentável: "Qual é a vantagem de ter uma casa, se você não tiver um planeta decente para colocá-la?".

Este aspecto também é comentado por Mikhailova (2004), que ao se referir ao capital natural, interpreta a sustentabilidade como a quantidade de consumo necessário para a sobrevivência das futuras gerações. Este Capital deve ser produzido através do estoque final do capital total, que se representa pela soma de capital material (produzido pelo homem), capital humano e capital natural. Nesse sentido, o capital natural é o de maior relevância para toda a humanidade, pois através de como é utilizado esse capital, e de que forma os seus recursos vão sendo repostos de volta para o planeta, é que conseguiremos definir o conceito de sustentabilidade (CALDWELL, 1984).

Segundo Motta e Aguilar (2009), a necessidade de manutenção ou melhoria no aspecto de vida requer medidas que proporcionem soluções eficientes na utilização dos recursos naturais, que causem menos efeitos negativos no meio ambiente. Nesse sentido, na busca por novas condições favoráveis de consumo, a sociedade almeja uma alternativa chamada desenvolvimento sustentável.

Ainda de acordo Motta e Aguilar (2009), a sustentabilidade alcança três vertentes essenciais para um desenvolvimento sustentável: a ligação entre social- cultural, ambiental e econômica, que necessita de interação entre elas para desenvolver uma ação eficaz diante da natureza. O desenvolvimento sustentável deve ser o reflexo desses três pilares (ELKINGTON, 2006).

Para Silva et al. (2019), pequenas mudanças no cotidiano e algumas ações simples do dia a dia podem influenciar uma comunidade que não está atenta a conceitos ambientais e sociais a adotarem e exigirem das organizações e pessoas com as quais se relacionam a adoção de práticas sustentáveis.

Considerando Silva, Barboza e Meiriño (2020), um outro ponto relevante que pode ser abordado dentro da educação para a sustentabilidade é a coleta, separação, reciclagem e reutilização de resíduos, que poderá trazer benefícios lucrativos gerando uma quantidade significativa de benefícios a todas as partes envolvidas.

A gestão de resíduos pode se basear Política Nacional de Resíduos Sólidos (PNRS), instituída pela Lei n 12.305, de 2 de agosto de 2010, que traz como princípios: proteção da saúde pública e da qualidade ambiental; não geração, redução, reutilização, reciclagem e tratamento dos resíduos sólidos, bem como disposição final ambientalmente adequada dos rejeitos; estímulo à adoção de padrões sustentáveis de produção e consumo de bens e serviços; adoção, desenvolvimento e aprimoramento de tecnologias limpas como forma de minimizar impactos ambientais; incentivo à indústria da reciclagem, tendo em vista fomentar o uso de matérias-primas e insumos derivados de materiais recicláveis e reciclados. Tal temática ao ser conduzida no ambiente escolar, no ensino de ciências, pode ser parte fundamental para o aprendizado dos alunos em questões ambientais.

De acordo com Souza et al. (2020) é comum que as instituições de ensino passem para outras empresas a responsabilidade sobre o lixo, o que é contrário à PNRS, que prevê uma responsabilidade compartilhada. Logo incluir esta abordagem na educação dos alunos pode fazer com que a escola cumpra este requisito ao contar com a participação dos discentes na gestão de resíduos.

A necessidade de se estabelecer uma ação efetiva nas práticas da civilização aumenta a quantidade de problemas ocasionados pela mesma, no que demanda a quantidade de consumo necessária para suprir suas necessidades (JAPPU \& FRANCISCON, 2018). O desenvolvimento sustentável precisa ser referido não somente em relação a ações locais que direcionem a sustentabilidade como num processo global em um todo (LUBIN \& ESTY, 2010).

Para que uma organização apresente resultados ambientais eficientes e eficazes, deverá atender de forma sistêmica e integrada aos requisitos legais, às demandas organizacionais e também das partes interessadas (BARBOZA et al., 2020)

O artigo 225 da Constituição Federal cita que:

Todos têm direito ao meio ambiente ecologicamente equilibrado, bem de uso comum do povo e essencial à sadia qualidade de vida, impondo-se ao poder público e à coletividade o dever de defendê-lo e preservá-lo para às presentes e futuras gerações (BRASIL, 1988).

Observa-se, de acordo com a Constituição, que em relação à questão ambiental, é necessário que se utilize de todos os meios que forma a assegurar esse direito, fazendo surgir na prática uma conduta mais rentável perante os recursos que o planeta nos oferece. A proteção de todos os ecossistemas propicia uma restauração ecológica na vida útil da natureza, e dos recursos disponíveis no país. O efeito relativo a essa lei delibera a forma de manuseio dos recursos naturais para a sociedade, e suas respectivas necessidades.

Segundo Barbosa (2008, p. 3), durante a Conferência de Ottawa (1986) foi estabelecidos cinco parâmetros para se conquistar o desenvolvimento sustentável: 
I. integraçãoda conservaçãoedodesenvolvimento;

II. satisfação das necessidades básicas humanas;

III. alcance de equidade e justiça social;

IV. provisão da autodeterminação social e da diversidade cultural;

V. manutenção da integração ecológica.

Compreende-se que as decisões tomadas em prol da execução desses critérios, analisam a interação da sociedade com o meio ambiente, e o que fazer dela a partir das decisões tomadas na manutenção do desenvolvimento sustentável (TISDEL, 1985). Além de suprir as noções básicas de consumo humano, o que caracteriza o desenvolvimento sustentável na busca pela sustentabilidade é a quantidade de recursos utilizados sobre aquilo que a natureza pode oferecer (MILBRATH, 1984). Sendo a demanda por vezes maior do que a natureza é capaz de suportar (PIRAGES, 1977).

De acordo com a nova agenda de desenvolvimento sustentável da ONU, foram propostos 17 objetivos a serem implementados por todos os países do mundo durante os próximos 15 anos, até 2030. São eles:

I. Acabar com a pobreza em todas as suas formas, em todos os lugares;

II. Acabar com a fome, alcançar a segurança alimentar e a melhoria da nutrição e promover a agricultura sustentável;

III. Assegurar uma vida saudável e promover o bem-estar para todos, em todas as idades;

IV. Assegurar a educação inclusiva, equitativa e de qualidade, bem como promover oportunidades de aprendizagem ao longo da vida para todos;

V. Alcançar a igualdade de gênero e empoderar todas as mulheres e meninas;

VI. Assegurar a disponibilidade e gestão sustentável da água e saneamento para todos;

VII. Assegurar o acesso confiável, sustentável, moderno e a preço acessível à energia para todos;

VIII. Promover o crescimento econômico sustentado, inclusivo e sustentável, emprego pleno e produtivo e trabalho decente para todos;

IX. Construir infraestruturas resilientes, promover a industrialização inclusiva e sustentável e fomentar a inovação;

X. Reduzir a desigualdade dentro dos países e entre eles;

XI. Tornar as cidades e os assentamentos humanos inclusivos, seguros, resilientes e sustentáveis;

XII. Assegurar padrões de produção e de consumo sustentáveis;
XIII. Tomar medidas urgentes para combater a mudança climática e seus impactos;

XIV. Conservação e uso sustentável dos oceanos, dos mares e dos recursos marinhos para o desenvolvimento sustentável;

XV. Proteger, recuperar e promover o uso sustentável dos ecossistemas terrestres, gerir de forma sustentável as florestas, combater a desertificação, deter e reverter a degradação da terra e deter a perda de biodiversidade;

XVI. Promover sociedades pacíficas e inclusivas para o desenvolvimento sustentável, proporcionar o acesso à justiça para todos e construir instituições eficazes, responsáveis e inclusivas em todos os níveis;

XVII. Fortalecer os meios de implementação e revitalizar a parceria global para o desenvolvimento sustentável.

Os pontos IV, XV e XVI consagram as verdadeiras intenções por uma humanidade mais justa e igualitária para todos. Fornecer um ambiente saudável para as gerações aumenta não só as chances de ter uma sociedade consciente sobre a natureza, como também na qualidade de vida. Proporcionar conhecimentos, de forma abrangente desperta o interesse e estimula o crescimento, para ocasiões como essa. O nível de conhecimento sobre o que nos rodeia, salienta sobre nossas próprias atitudes, sejam elas boas ou ruins. $\mathrm{O}$ grande foco dessas intenções é fazer um bom consumo do que temos, garantindo que outras gerações possam usufruir de forma ainda melhor tudo o que o meio ambiente nos oferece.

\section{LEVANTAMENTO}

Como técnica de coleta de dados, foram utilizadas entrevistas, devido ao fato de pesquisador ter um contato mais direto com os entrevistados, podendo perceber as opiniões acerca do assunto. Tal técnica utilizou perguntas aos entrevistados como forma de aquisição de informações específicas. Embora tenha havido o planejamento das perguntas essas serviram apenas para guiar as entrevistas de maneira semiestruturada, que permitiu uma maior liberdade dos respondentes (PEREIRA et al., 2018).

Como referências para elaboração do inquérito, foram utilizadas as referências das citações sobre a temática utilizadas ao longo do artigo, os PCN (Parâmetros curriculares nacionais), art 225 e ProNEA (Programa nacional de educação ambiental) .

O recorte no ensino básico é justificado, pois é nele que começam a se formar os profissionais do futuro e as percepções dessas crianças que possibilitaram o desenvolvimento econômico, social e ambiental da sociedade, logo é importante que os conceitos de sustentabilidade 
estejam diretamente atrelados a sua formação. Assim o estudo foi realizado em seis escolas de educação pública geridas pelo município de Araruama.

A prática ambientalista discorre não somente do meio local, como internacional. Investir na mudança promovendo aquisições de uma nova estrutura sustentável alcança novos pontos de vista sobre o equilíbrio dos recursos. Na regulamentação dos mesmos, a atribuição da educação se faz ativa, seguido do princípio de que a Educação Ambiental, quando bem aplicada, propiciando a conscientização e interação de indivíduos numa sociedade perante os problemas ambientais.

Se definiu que o público entrevistado seriam de professores e coordenadores pedagógicos, pois os professores estão diretamente a aplicação de conteúdos, tendo interação com os alunos, e os coordenadores estão podem proporcionar um ambiente educacional onde a sustentabilidade seja praticada como um estilo de vida de todos os envolvidos.

Mediante isto, a relação de ensino se faz presente para estimular o crescimento no conhecimento sobre o ambiente à sua volta e como mantê-lo para as futuras gerações. A educação ambiental trás novas perspectivas observando-se a relação do aluno com o seu meio. O desenvolvimento do tema trabalha meios que são vinculados a identidade dos alunos para a formação de pessoas conscientes com o entorno socioambiental numa escala global. A motivação por aprender práticas que influenciam no seu modo de vida, libera uma troca de conhecimentos, experimentos e vivências, que produzidos no âmbito em que aprendem, conscientizam a relação do ser humano com a natureza (BRASIL, 1997).

Este aspecto também é comentado pelo Programa Nacional de Educação Ambiental, que enfatiza sobre práticas por um país mais justo e sustentável. O programa atua em ações que assegurem as múltiplas variações de sustentabilidade no processo educacional. Diante dessas práticas o Programa Nacional de Educação Ambiental (2005, p. 23) preconiza as seguintes diretrizes:

I. Transversalidade e Interdisciplinaridade.

II. Descentralização Espacial e Institucional.

III. Sustentabilidade Socioambiental.

IV. Democracia e Participação Social.

V. Aperfeiçoamento e Fortalecimento dos Sistemas de Ensino, Meio Ambiente e outros que tenham com a educação ambiental.

A atuação dessas diretrizes, em conjunto com as políticas de governo, faz- se necessária perante um processo de transformação como um todo, com iniciativas que estimulem a percepção da sociedade, a fim de fortalecer a implementação da educação ambiental no âmbito social e escolar (BRASIL, 2005).

Ainda de acordo com a Agenda 21 (BRASIL, 2004), a educação deve ser o instrumento fundamental de mudança para a implementação do novo paradigma da sustentabilidade. A agenda contempla ações voltadas para a "promoção da cultura da sustentabilidade, valores como a ética, solidariedade, cooperação, afetividade e espiritualidade" (BRASIL, 2004, p. 34).

Nesse mesmo sentido, de acordo com o que se é proposto em relação à educação ambiental, é importante trabalhar promovendo atitudes que forneçam equilíbrio ao se utilizar os recursos ambientais, com formação de valores que busquem o entendimento sobre seus próprios atos, formando cidadãos que busquem preservar e meIhorar o ambiente. Deve-se trabalhar com informações para que os alunos possam ampliar seus conhecimentos sobre o ambiente em que vivem, comparando sua realidade com as de outros meios (BRASIL, 1997).

De acordo com os PCN - Temas Transversais Meio ambiente (BRASIL, 1997, p.209):

Informações a respeito de possibilidades de uso diferente da água em outras culturas, da viabilidade de sua reutilização e da redução de desperdício na sociedade industrial dão aos alunos subsídios para defender transformações no gerenciamento desse recurso natural, apontando para a sustentabilidade e para o desenvolvimento de atitudes pessoais coerentes.

Compreende-se que buscar conhecimento a respeito do local onde as pessoas (alunos) estão inseridas e compará-las com outros ambientes, contribui para melhor entendimento sobre a produção e preservação dos recursos a serem consumidos, destacando-se o importante papel dos educadores ao estimular o pensamento crítico de seus alunos a partir do conhecimento e das experiências adquiridas. A construção do conhecimento na temática ambiental é de necessidade contínua, permitindo ao aluno a percepção e atualização constante sobre esse saber (BRASIL, 1997).

É preciso desenvolver em nossos alunos uma mudança de atitude em relação à preservação do meio ambiente, objetivando a sustentabilidade, sendo importante destacar que essa atitude não é construída apenas com informação. "É preciso que a escola se organize para que em seu ambiente essas atitudes possam ser praticadas. Seja na forma de situações didáticas intencionalmente planejadas, seja no dia-a-dia escolar" (BRASIL, 1997, p.210). 


\subsection{Sustentabilidade no ensino de Ciências}

Com o objetivo de buscar melhor entendimento sobre a temática, desenvolveu-se pesquisa empírica, de caráter qualitativo, com base nos depoimentos de professores que lecionam no ensino de Ciências e coordenadores pedagógicos que atuam na Educação Básica do município de Araruama/RJ.

Araruama é um município dentro uma das 11 regiões turísticas do Estado do Rio de Janeiro, a Região dos Lagos, que possui praias procuradas para a prática do surf e do mergulho, e com lagoas de grande apelo paisagístico e grande potencial para as atividades náuticas e balneárias (MATTOS, et al., 2019) e que devido a sua dimensão e importância necessita de observância quanto aos quesitos para o desenvolvimento sustentável que podem se basear na educação.

O município de Araruama não tem grandes dimensões tendo o estudo se baseado apenas em seus limites, logo a quantidade de profissionais entrevistados se deu de acordo com a facilidade de acesso a estes e de acordo com a quantidade que se dispôs a participar da pesquisa, visto que os demais prospectados não aceitaram participar do levantamento.

O critério de escolha dos professores e coordenadores, se deu devido ao fato de estes atuarem em escolas públicas municipais em Araruama.

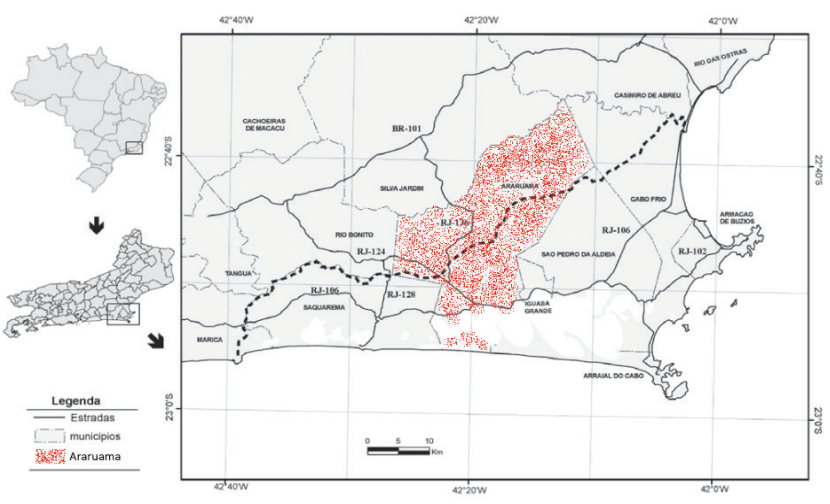

Figura 2 - Localização do Município de Araruama Fonte: Adaptado de Bohrer et al., 2009

Os professores e coordenadores entrevistados responderam a algumas questões a respeito de como costumam desenvolver a temática sobre sustentabilidade no ensino de Ciências e quais as situações didáticas intencionalmente planejadas por professores e coordenadores. $\mathrm{Na}$ pesquisa empírica foram entrevistados dois grupos, um com três professores e um com três coordenadores. As questões das entrevistas realizadas estão disponíveis nos apêndices, entretanto foram realizadas de maneira aberta, de modo que os professores e coordenadores tiveram liberdade de responder como julgassem adequado, tendo as questões cunho apenas norteador.

\subsubsection{Análise das entrevistas com os professores}

As entrevistas buscaram dar liberdade aos professores para falarem de suas experiências sobre o tema, porém foram guiadas pelas seguintes perguntas:

1. Até 2030, a ONU deseja implementar 17 objetivos em busca do desenvolvimento sustentável por todo o mundo. Dentre esses objetivos, destaca-se "assegurar a educação inclusiva, equitativa e de qualidade, bem como promover oportunidades de aprendizagem ao longo da vida para todos".

2. De que forma o ensino de Ciências em sala de aula pode ser uma ferramenta de auxílio para o desenvolvimento desses objetivos?

3. Com base no artigo 225 da Constituição Federal, viver em um ambiente ecologicamente equilibrado é direito de todos.

4. De que forma a escola pode ser um caminho para o efetivo cumprimento dessa lei?

5. Proteger e cuidar são algumas atitudes que possibilitam o uso contínuo dos recursos consumidos pela sociedade. A escola em que trabalha (ou já trabalhou) desenvolve projetos buscando o despertar dessa consciência? Como são esses projetos?

6. Em suas aulas de Ciências, como você costuma desenvolver a temática sobre sustentabilidade no ensino de Ciências e quais as situações didáticas intencionalmente planejadas?

O professor A é graduado em Ciências Biológicas, e mestre em Biologia Vegetal, atuando durante seis anos em cursos preparatórios militares e pré-vestibulares, incluindo escolas públicas dos municípios de Araruama e Saquarema/ RJ, e também no Ensino Superior.

Analisando as respostas do professor $\mathrm{A}$, em relação ao tema sustentabilidade no ensino de Ciências, o professor entende que é possível apresentar uma melhor evolução de acordo com a infraestrutura em que o ensino é inserido na escola, propiciando melhor aprendizado e vivência aos alunos.

O professor A destaca que, nesse sentido, é importante abordar temas que estimulem a prática e o entendimento sobre as causas sustentáveis de forma inclusiva ao ambiente escolar. Este professor diz compreender que a implementação de projetos sustentáveis na disciplina de Ciências é importante para que os alunos tenham mais 
conhecimento sobre as questões ambientais e que busca sempre desenvolver projetos interdisciplinares com as outras matérias, entretanto não esclarece quais são as atividades que desenvolve em prol da prática sustentável.

Práticas possíveis de serem abordadas poderiam estar relacionadas a reciclagem, hortas caseiras, redução do consumo de água e energia, entre outros.

O professor atentou que, muitas das vezes, os recursos necessários para o funcionamento das atividades não são adquiridos pelas escolas, dificultando o processo ensino aprendizagem. Tal posicionamento crítico coincide com o plano de ação da ONU para os próximos anos sobre o desenvolvimento sustentável, que ressalta a necessidade de construir infraestruturas necessárias para o aperfeiçoamento dos alunos e também das instituições, de modo a implementar o acesso a educação com direito inclusivo ao desenvolvimento sustentável para todos.

O segundo professor entrevistado é graduado em licenciatura em Ciências Biológicas, mestre em Dinâmicas dos Oceanos da Terra, atuando durante nove anos em escola privada e há quatro anos no Ensino Superior. Aqui denominado como professor $\mathrm{B}$.

Para o professor $B$, as leis vigentes sobre educação ambiental não são suficientes para incentivar o desenvolvimento do tema nas escolas, de forma a fazer parte do currículo pedagógico. O professor entende que, algumas vezes, mesmo que as instituições saibam que existem medidas a serem implementadas, e que muitas delas podem promover o melhor rendimento dos alunos, não há desejo em aplicação, pois é requerido um esforço e maior atenção aos demais assuntos na grade curricular. De acordo com os Parâmetros Curriculares Nacionais (BRASIL, 1997), a escola precisa mudar essa atitude, pois é necessário que ela "se organize para que em seu ambiente essas atitudes possam ser praticadas. Seja na forma de situações didáticas intencionalmente planejadas, seja no dia-a-dia escolar".

Segundo o professor B, a delimitação aos conteúdos pedagógicos impede a influência sobre investir e estimular a aquisição de um ambiente saudável entre todos no meio escolar. Não são motivados a exercer determinada função, pois sua realidade de trabalho é outra. É direcionado somente a passar o conteúdo do livro, tendo que, algumas vezes, adiantar assuntos para conseguir cumprir com toda a grade ao final do ano letivo; a não ser que, durante o processo de ensino, os próprios professores despertem nos alunos outros interesses, além dos livros. Para o professor B, "a falta de informação e regularização diminuem os índices de recursos propícios para o desenvolvimento de um novo pensar e agir diante das necessidades sustentáveis".
O terceiro entrevistado é uma professora (aqui denominada como C), que possui graduação em Biomedicina, licenciatura em Ciências Biológicas, mestrado e doutorado em Ciências Biológicas (Biofísica). Em exercício há 17 anos, com experiência no Ensino Fundamental (educação pública) e Ensino superior.

A professora $C$ entende que a disciplina de Ciências pode ser uma ferramenta de auxílio para desenvolvimento de objetivos sustentáveis, conforme o ensino é passado aos alunos. De acordo com a professora C, "durante a aplicação dos conteúdos de Ciências em sala de aula, o aluno tende a compreender sobre as ações no ambiente em que vive e sobre as maneiras existentes de se integrar a sociedade de forma consciente". Tal observação vai ao encontro dos Parâmetros Curriculares Nacionais (BRASIL, 1997), quando afirma que "deve-se trabalhar com informações para que os alunos possam ampliar seus conhecimentos sobre o ambiente em que vivem, comparando sua realidade com as de outros meios". A professora observa que para isso, é necessária a busca pelo aluno em entender sobre esses assuntos, e o auxílio do sistema para que esse aluno venha ter acesso à educação.

A professora $C$ observou que, antes de se colocar as leis existentes em vigor no espaço escolar, as instituições precisam entender o que significa estar dentro de um ambiente ecologicamente equilibrado. A continuidade desse processo deve-se à extensiva conduta de órgãos competentes, para que haja qualidade no gerenciamento de escolas, a qual se proponha a estabelecer um ambiente mais saudável para todos os que vivenciam o espaço escolar. As observações da professora entrevistada corroboram ao que está publicado no artigo 225 da Constituição Federal (BRASIL, 1988), quando afirma que "todos têm direito ao meio ambiente ecologicamente equilibrado, bem de uso comum do povo e essencial à sadia qualidade de vida".

De acordo com a professora C, o ensino de Ciências deve ser introduzido com metodologias que propiciem o entendimento crítico e reflexivo dos alunos, de forma sútil e com diálogo permanente, "que após tratarem de assuntos comuns à sua vida social em sala de aula, eles consigam administrar suas ações, resultantes de uma vida ecologicamente saudável". A professora afirma ainda que é necessário que exista interação de toda a comunidade escolar para que ocorra um resultado ainda mais satisfatório.

O trabalho de Barbosa (2008) relata justamente sobre essa intenção, ao analisar a interação da sociedade com o meio ambiente, e o que fazer dela a partir de suas ações. O autor sustenta que, ao mesmo tempo, é necessário 
adquirir a manutenção da integração ecológica, não só em ambiente de ensino, como em todas as áreas que estimulem a educação por um desenvolvimento sustentável.

\subsubsection{Análise das entrevistas com os coorde- nadores pedagógicos}

Para orientar as entrevistas com os coordenadores pedagógicos, foram feitas três perguntas, conforme a seguir:

1. De acordo com os PCN - Temas Transversais Meio ambiente, é necessário desenvolver nos alunos uma mudança de atitude em relação à preservação do meio ambiente, objetivando a sustentabilidade. Como a escola pode contribuir para promover essa mudança de atitude?

2. O ensino de Ciências/Biologia costuma concentrar boa parte das "situações didáticas intencionalmente planejadas" em relação à temática ambiental. Como promover ações para que o ensino de Ciências trabalhe em parceria com as outras disciplinas?

3. Em sua experiência como gestor/coordenador pedagógico, quais as principais dificuldades em promover na escola uma mudança de atitude em relação à questão ambiental?

O primeiro coordenador pedagógico é graduado em Pedagogia e Matemática, com mestrado em Educação Básica, com experiência profissional como professor da Educação Básica, Ensino Superior, gestão escolar e coordenador, somando um total de quatorze anos de experiência na profissão. Aqui denominado como coordenador A.

Para este profissional, muitos dos planos fornecidos pela escola podem ser remanejados a fim de fomentar a prática da sustentabilidade no dia a dia escolar. O que democratiza a intenção de investimento para a mudança de um hábito mais saudável sobre o grupo envolvido. A mobilização e progressão tornam-se dependentes de esforços, que devem gerar exemplos para a coletividade, podendo promover a conscientização e reflexos de impactos, resultantes da prática sobre a sustentabilidade.

O coordenador A afirma que durante o processo de formação do professor, ele precisa entender e conhecer sobre os meios de instrumentação no ensino para expor suas práticas junto às demais disciplinas, servindo de orientação para o determinado assunto.

É fundamental que o docente entenda de Transversalidade e seja levado a elaborar ações que permitam esse diálogo entre o "dentro e o fora" do currículo. Assim, haverá uma liberação para que disciplinas estejam juntas em um trabalho coletivo de estudos e consciência sobre o assunto.
As colocações do coordenador A, ao refletir sobre quais são as principais dificuldades em promover na escola uma mudança de atitude em relação à questão ambiental, está relacionada a dificuldade de se criar exemplos e a coerência dos agentes participativos para essa tamanha conscientização. Ao tentar resolver os problemas, acabam sendo criados outros, suprindo o consumo sem avaliar o que isso custará na demanda.

Tal reflexão vem ao encontro de Mikhailova (2004), que ao dizer sobre o capital natural, atenta-se sobre a manipulação desses recursos naturais mediante ao consumo necessário para se manter parte da vida na Terra. Para ocorrer um equilíbrio ambiental, é necessário investir adequadamente o capital natural (florestas, água, ar), conscientizando as condições do hoje, com busca no que for sobreviver para o amanhã.

Ou seja, o que o coordenador A destaca é sobre as questões de comportamento e entendimento perante as causas sustentáveis no espaço escolar, não sofrendo por vezes estímulos ou intenção de prática. O meio de se conscientizar começa por toda a sociedade, não basta promover condições favoráveis a um momento específico, e sim a todos os momentos promover mudanças.

A segunda coordenadora (aqui denominada como B) é doutora em Psicologia, mestre em Educação, especialista em Administração Escolar, Licenciada em Pedagogia. Com experiência de trinta e seis anos na área de educação, seja como professora, gestora e coordenadora pedagógica.

Para a coordenadora B é necessário que sejam desenvolvidas ações educativas sobre questões e problemas ambientais, através de métodos ativos, conscientizando sobre a necessidade de proteção e preservação do meio ambiente.

A educação ambiental na escola é hoje o instrumento muito eficaz para se conseguir criar e aplicar formas sustentáveis de interação sociedade-natureza. Este é o caminho para que cada indivíduo mude de hábitos e assuma novas atitudes que levem à diminuição da degradação ambiental, promovam a melhoria da qualidade de vida e reduzam a pressão sobre os recursos ambientais.

Para a entrevistada, é preciso despertar a conscientização referente ao meio ambiente, como faz notar as propostas de ações da ONU, que propõe ações para proteger, recuperar e promover o uso da natureza de forma sustentável.

A coordenadora $B$ relata que a educação ambiental é hoje um instrumento eficaz para conseguir criar e aplicar formas sustentáveis, em uma relação harmoniosa entre a sociedade e a natureza. "Fazer com que cada indivíduo tenha percepção de onde vive, é um caminho para novos hábitos e práticas conscientes, melhorando a qualidade vida". 
Ao ser indagada sobre a importância de promover ações para que o ensino de Ciências trabalhe em parceria com outras disciplinas, a coordenadora B comentou a respeito da interdisciplinaridade:

Os temas discutidos na educação ambiental quando trabalhados numa perspectiva de interdisciplinaridade proporcionam situações significativas aos alunos e favorecem para a construção crítica dos saberes. A Educação Ambiental possui elementos onde podem ser abordados vários temas contemporâneos, abarcando os vários contextos históricos e econômicos, envolvendo história, geografia, matemática, filosofia, sociologia, e outras disciplinas.

Observa-se na fala da coordenadora B, o que foi preconizado nas diretrizes do Programa Nacional de Educação Ambiental (BRASIL, 2005) sobre a necessidade da transversalidade e interdisciplinaridade. Além disso, a coordenadora $B$ aponta para a transversalidade do tema educação ambiental com os diversos temas que envolvem a história e a economia, corroborando o que foi mencionado nos Parâmetros Curriculares Nacionais - temas transversais Meio Ambiente (BRASIL, 1997).

Ao levar em consideração outro ponto destacado pela coordenadora $\mathrm{b}$, atenta-se que o maior problema seja a falta de conhecimento teórico sobre o assunto, muitas vezes desconhecido pelos professores, "precisamos ofertar aos professores oportunidade de estudo sobre o tema, através de cursos de formação continuada, de projetos escolares e outras formas significativas".

A terceira coordenadora é graduada em Pedagogia, pós-graduada em Tecnologia Educacional e Educação Inclusiva. Atuando na profissão há trinta e cinco anos como professora, gestora e coordenadora, em instituições de ensino público e privado. Para a coordenadora $C$, a escola pode contribuir para a formação de uma consciência ambiental em seus alunos, promovendo ações e projetos que os façam pesquisar e buscar refletir sobre o seu papel como cidadão na preservação do meio ambiente.

Quando questionada sobre como promover ações para que o ensino de Ciências trabalhe em parceria com as outras disciplinas, a coordenadora $\mathrm{C}$ apontou a necessidade da interdisciplinaridade e transversalidade, corroborando a fala dos outros coordenadores e com os PCNS (BRASIL, 1997). A entrevistada afirmou que na escola em que trabalha "é comum a prática de projetos interdisciplinares, e tem feito muito sucesso".

A respeito das principais dificuldades em promover na escola uma mudança de atitude em relação à questão ambiental, a coordenadora $\mathrm{C}$, assim como os demais entrevistados, reforçou a necessidade de aprofundamento sobre o assunto, para depois repassar aquilo que se entendeu e foi posto em prática como um hábito comum para uma melhor qualidade de vida. Segundo a coordenadora C, o reforço é necessário, pois "infelizmente, por mais que se trabalhe sobre a questão ambiental, os alunos em suas atitudes parecem que esquecem muito rápido o que foi aprendido nos projetos e em sala".

Percebe-se, portanto, que a maioria dos entrevistados aponta para a necessidade de situações didáticas intencionalmente planejadas para que o tema educação ambiental seja uma constante na escola, observando que toda a comunidade escolar pode, e deve ser envolvida, partindo sempre do que acontece em seu entorno, buscando uma mudança de atitude para que a natureza seja utilizada de forma sustentável.

Sintetizando as entrevistas, é percebido que os objetivos do desenvolvimento sustentável não são efetivamente trabalhados no cotidiano escolar e mesmo a educação ambiental ocorre em alguns discursos, mas não é trabaIhada em práticas como a da gestão de resíduos.

\section{CONSIDERAÇÕES FINAIS}

A escola é um lugar de aprendizado e desenvolvimento de saberes. Nela está tudo o que envolve conhecimento e a percepção de crescimento para se desenvolver tais critérios de ensino-aprendizagem. O uso efetivo da sustentabilidade não está somente relacionado a Ciências, mas a todas as formas de conhecimento que forneçam ao aluno um pensamento crítico reflexivo sobre suas condutas diante do ambiente onde vive, e dos recursos oferecidos para que esse indivíduo viva de forma digna e consciente.

Nesse sentido, a escola representa uma importante ferramenta para promover estímulos que levem a grandes ensinamentos a respeito da vida humana e da natureza em seu entorno. Os educadores precisam estar dispostos a exercer tamanha função mobilizadora e devem estar antenados e buscando capacitação para estimular em seus alunos uma consciência e prática sustentável. Os alunos, por sua vez, precisam estar atentos para absorver os ensinamentos e disseminar o conhecimento para a comunidade em que vive.

As leis citadas ao longo do trabalho contribuíram para os resultados como aquisição de novas perspectivas no ambiente de trabalho para os profissionais da área, onde a sustentabilidade pode ser dirigida com fator fundamental para crescimento e desempenho dos alunos frente a sociedade e o ambiente onde vivam, norteando as ações dos educadores. 
Este artigo contribuiu para a discussão de como a prática da sustentabilidade na escola é capaz de desenvolver uma mudança de atitude em relação à preservação do meio ambiente, propondo uma discussão sobre a temática não somente no ensino de Ciências, mas que organiza na escola um ambiente onde essas atitudes possam ser praticadas.

Espera-se que essas reflexões possam inspirar formas regulares de prática sustentável no ambiente escolar, como a aplicação de metodologias ativas para o desenvolvimento de competências sustentáveis, por exemplo, mesmo compreendendo que ainda há necessidade de maior discussão sobre a temática, observando a necessidade de aprimoramento e entendimento de novas modalidades de ensino.

\section{AGRADECIMENTOS}

À todos os profissionais que solicitamente colaboraram ao serem entrevistados para o desenvolvimento dessa pesquisa.

\section{REFERÊNCIAS}

Agenda 21 brasileira: ações prioritárias. Comissão de Políticas de Desenvolvimento Sustentável e da Ambiente, 2004.

BARBOSA, G. S. O desafio do desenvolvimento sustentável. Revista Visões $4^{a}$ Edição, N\$4, Volume 1 - Jan/ Jun, 2008.

BARBOZA, D. V. et al. Aplicação da Economia Circular na Construção Civil. Research, Society and Development, Itabira, v. 8, n. 7, e9871102, 2019.

BARBOZA, D. V. et al. Avaliação da Geração Eólica como Alternativa ao Descomissionamento de Plataformas Petrolíferas Fixas nos Mares Brasileiros. Anuário do Instituto de Geociências, Rio de Janeiro, v. 43, n. 3, 455-466, 2020.

BRASIL. Constituição da República Federativa do Brasil de 1988. Disponível em <http://www.senado. leg.br/atividade/const/con1988_06.06.2017/art225-. asp. Acessado em outubro 2018.

BRASIL. Decreto n 7.404, de 23 de dezembro de 2010. Regulamenta a Lei no 12.305, de 2 de agosto de 2010, que institui a Política Nacional de Resíduos Sólidos, cria o Comitê Interministerial da Política Nacional de Resíduos Sólidos e o Comitê Orientador para a Implantação dos Sistemas de Logística Reversa, e dá outras providências. Diário Oficial da União, Brasília, 23 dez. 2010. Disponível em: <http://www.planalto.

gov.br/ccivil_03/_Ato2007-2010/2010/Decreto/D7404. htm>. Acesso em:

BOECHAT, C.; AMARAL, L. A. Abordagens para a sustentabilidade nas organizações, Caderno de Ideias, v. 1, FDC - Núcleo Petrobras de Sustentabilidade, 2012. BOFF, L. Sustentabilidade: o que é - o que não é. Petrópolis: Vozes, 2012.

BOHRER, C. B. A. et al. MApeamento da Vegetação e do Uso do Solo no Centro de Diversidade Vegetal de Cabo Frio, Rio de Janeiro, Brasil. Rodriguésia, Rio de Janeiro, v. 60, n. 1, 01-23, 2009.

CALDWELL L. K. 1984. Political aspects of ecologically sustainable development. Environmental Conservation 11:299-308.

Carta deOttawa. Primeira Conferência Internacional sobre a Promoção da Saúde, Ottawa,1986. Disponível em www.opas.org.br

ELKINGTON, J. Corporate Sustainability and the Triple Bottom Line Approach, 2006.

ELKINGTON, J.: Triple bottom line revolution: reporting for the third millennium. Australian CPA, v. 69, p. 75, 1999.

GONÇALVES, V. S; GONÇALVES-JÚNIOR, E. R; ROCHA, D. L.; GONÇALVES, B. S. Análise de Casos Múltiplos no Setor Hoteleiro quanto a Sustentabilidade e Gestão Ambiental. Revista de Trabalhos Acadêmicos Lusófona, São Gonçalo, v. 2, n. 2, p. 169-181, 2019.

JAPPU, R. F; FRANCISCON, M. Indicadores de Sustentabilidade para uma Organização do Segmento da Construção Civil Pesada. Mix Sustentável, Florianópolis, v. 4, n. 3, p. 97-102, 2018.

LUBIN, D.A., ESTY.D.C. The Sustentability Imperative: Lessons for leaders from previous game-changing megatrends. Harvard Business Review, pp 43-50, 2010. MATTOS, A. K. M. et al. Aplicação do método NASA-TLX para avaliação da carga de trabalho em uma operadora de serviços de saúde na região dos lagos. Brazilian Journal of Production Engineering, São Mateus, v. 5, n.2, p. 31-43, 2019.

MIKHAILOVA, I. Sustentabilidade: Evolução dos conceitos teóricos e os problemas da mensuração prática. Revista Economia. № 16, 2004.

MILBRATH, L. W. 1984. A proposed value structure for a sustainable society. Environmentalist 4:113-124.

MILLER, G. Tyler; SPOOLMAN, Scott E. Ecologia e Sustentabilidade. Tradução da $\sigma^{\text {a }}$ edição norte-americana. Editora Cengage Learning, 2012.

MOTTA, S.; AGUILAR, M. Sustentabilidade de projetos de edificações. Gestão \& Tecnologia de Projetos Vol. 
4, $\mathrm{n}^{\circ} 1$, Maio de 2009.

MUNIZ, J. P. S.; PAZMINO, A. V. O design na educação ambiental: Requisitos para kit interdisciplinar sobre a perda da biodiversidade. Mix Sustentável, Florianópolis, v. 5, n. 2, p. 55-70, 2019.

Parâmetros Curriculares Nacionais - Meio ambiente. Brasília: MEC, 1997.

PEREIRA, A. S.; SHITSUKA, D. M.; PARREIRA, F. J.; SHITSUKA, R. Metodologia da pesquisa científica. Editora UAB/NTE/UFSM. Santa Maria-RS. 2018. PIRAGES , D. (ed.). 1977. The sustainable society: implications for limited growth. Praeger, New York.

Programa nacional de educação ambiental - ProNEA / Ministério do Meio Ambiente. 3. ed - Brasília: Ministério do Meio Ambiente, 2005. 102p

SILVA, D. V. S.; BARBOZA, D. V.; MEIRIÑO, M. J. Reverse post-consumption cycle for a paper items manufacturing industry. Journal of Engineering and Technology for Industrial Applications, v. 6, n. 24, p. 47-52, 2020.

SILVA, J. F; BELLA, R. L. F.; BARBOZA, D. V.; MEIRIÑO, M. J. Sustentabilidade em Microescala: Estudo de Caso de Uma Padaria de Bairro. MIX Sustentável, Florianópolis, v. 5, n. 3, p. 93-102, jul. 2019.

SOUZA, L. O. G. R.; BARBOZA, D. V.; MEIRIÑO, M. J.; SILVA, F. A. Sustainable management of food waste in federal universities: a documentary analysis of strategies in Brazilian Southeast. Research, Society and Development, v. 9, n. 8, p. e292985763, 2020. DOI: 10.33448/rsd-v9i8.5763

TISDELL , C. 1985. World conservation strategy, economic policies, and sustainable resource-use in developing countries. Environmental Professional 7:102-107.

\section{AUTORES}

ORCID: http://orcid.org/0000-0001-5591-4211

VERÔNICA BATISTA DE LIMA | Faculdade Unilagos | Ciências Biológicas | Araruama, RJ - Brasil | Correspondência para: Av. Henrique Terra, 765 - Itajuru, Cabo Frio - RJ, 28915-115 |

E-mail: veronicabatistadelima@gmail.com

ORCID: http://orcid.org/0000-0002-2653-8541

DOUGLAS VIEIRA BARBOZA, M.Sc. | Universidade Federal Fluminense | Programa de Pós-Graduação em Sistemas de Gestão Sustentáveis | Niterói, RJ - Brasil | Correspondência para: R. Passo da Pátria, 156 - Bloco E, Sala 324 - São Domingos, Niterói - RJ, 24210-240 | E-mail: douglasbarboza@id.uff.br

ORCID: http://orcid.org/0000-0001-9165-2300

MARCELO JASMIM MEIRIÑO, Dr. | Universidade Federal Fluminense | Programa de Pós-Graduação em Sistemas de Gestão Sustentáveis | Niterói, RJ - Brasil | Correspondência para: Avenida Roberto Silveira 307 ap 401- Icaraí - RJ, 24230-152 | E-mail: marcelojm@id.uff.br

ORCID: http://orcid.org/0000-0003-2212-1789

RICARDO LUIZ FERNANDES BELLA, Dr. | Universidade Federal Fluminense | Programa de Pós-Graduação em Engenharia de Produção e Sistemas Computacionais | Rio das Ostras, RJ - Brasil | Correspondência para: Rua Recife, s/n, Jardim Bela Vista, Rio das Ostras, RJ 28895-532 | E-mail: ricardobella@id.uff.br

\section{COMO CITAR ESTE ARTIGO}

LIMA, Verônica Batista de; BARBOZA, Douglas Vieira; MEIRIÑO, Marcelo Jasmin; BELLA, Ricardo Luiz Fernandes. Prospectando Horizontes Para O Ensino Integrado Da Sustentabilidade Na Educação Básica. MIX Sustentável, [S.I.], v. 7, n. 1, p. 125-136, dez. 2020. ISSN 24473073. Disponível em:<http://www. nexos.ufsc.br/index.php/mixsustentavel>. Acesso em: dia mês. ano. doi:https://doi.org/10.29183/2447-3073. MIX2020.v7.n1.125-136.

DATA DE ENVIO: 28/06/2020

DATA DE ACEITE: $16 / 10 / 2020$ 
